\title{
COMUNICAÇÃO
}

\section{LEVANTAMENTO DE RECONHECIMENTO COM APOIO DIGITAL DOS SOLOS DO MUNICÍPIO DE NAZARENO-MG ${ }^{1}$}

\author{
Digital reconnaissance soil survey of Nazareno, state of Minas Gerais
}

\author{
Ivana de Marco Fonseca Horta², José Aldo Alves Pereira ${ }^{3}$, João José Marques ${ }^{4}$, Luís Marcelo Tavares de Carvalho 5
}

\begin{abstract}
RESUMO
Este trabalho foi realizado no Município de Nazareno-MG, que tem sido submetido a sérios problemas ambientais em razão do uso inadequado dos solos, os quais, como suporte dos ecossistemas e das atividades antrópicas sobre a terra, são importantes para explicar fenômenos de erosão e assoreamento. Objetivou-se produzir um levantamento de reconhecimento de média intensidade dos solos, visando a subsidiar futuros mapeamentos mais detalhados do local. A escolha da área de trabalho deveu-se ao elevado grau que os processos erosivos alcançaram no município. Os sistemas de informações geográficas (SIGs) auxiliaram durante a investigação e a confecção dos mapas, minimizando custos e aumentando qualidade e precisão dos resultados. Foram definidas cinco unidades de mapeamento: Latossolo Vermelho-Amarelo distrófico típico (LVAd 1 a 4) (58\%), predominante, seguida por Cambissolo Háplico Tb distrófico típico (CXbd 4 a 6) (16\%) e CXbd 1 a 3 (15\%), a unidade Latossolo Vermelho distrófico típico (LVdf 1 a 4) (7\%) que ocorreu no norte do município e a unidade Gleissolo Háplico Tb distrófico típico (GXbd) que ocupa a menor área (2\%).
\end{abstract}

Termos para indexação: Mapeamento de solos, sistema de informação geográfica e pedologia.

\section{ABSTRACT}

This research was carried out in Nazareno County, State of Minas Gerais, which has been subjected to serious environmental problems due to inadequate soil use. Information about soils is necessary for the appropriate monitoring when implementing measures to mitigate or correct the problem. The objective of this work was to produce a soil recognition map. It is intended to subsidize future and more detailed mapping of the area. The choice of the work area was due to the high degree that the erosive processes reached in Nazareno. Geographic Information Systems (GIS) aided the mapping process and the investigation, minimizing costs and increasing the quality and precision of the results. Five soil mapping units were defined: LVAd (58\%) was predominant, followed by CXbd2 (16\%), and CXbd1 (15\%). The unit LVdf (7\%) occurs in the north of the municipal district and the unit GXbd occupies the smallest area (2\%).

Index terms: Soil survey, geographic information system, pedology.

(Recebido em 22 de novembro de 2006 e aprovado em 2 de fevereiro de 2009)

O solo é um corpo natural organizado, uma vez que possui horizontes originados por processos pedogenéticos que o distinguem das rochas e sedimentos (Fanning \& Fanning, 1989). Ele suporta toda a cobertura vegetal e, sobre ele, o Homem realiza o uso e a ocupação do espaço (Bertoni \& Lombardi Neto, 1990). A partir de um amplo diagnóstico do solo, torna-se possível inferir sobre sua potencialidade e fragilidade como elemento natural, recurso produtivo, substrato de construções e concentrador de impactos etc., tornando-se, sua análise e classificação imprescindíveis ao planejamento (Santos, 2004).

O reconhecimento das classes de solo pode se dar de variadas maneiras e para os mais diversificados fins
(Galeti, 1989). Dentre os fatores que auxiliam na identificação, a topografia e a posição da paisagem são relevantes uma vez que geram variadas influências nas propriedades dos solos, mesmo quando esses são fortemente intemperizados e possuem um grau elevado de homogeneidade (Curi \& Franzmeier, 1984).

De acordo com Resende et al. (2002), cada classe de solo corresponde a uma unidade taxonômica. Por sua vez, uma ou várias unidades taxonômicas constituem uma unidade de mapeamento que levam, geralmente, o nome da unidade taxonômica dominante. As associações de solos são agrupamentos de unidades taxonomicamente definidas que ocorrem juntas no espaço geográfico em

\footnotetext{
${ }^{1}$ Parte da Dissertação de Mestrado do primeiro autor.

${ }^{2}$ Geógrafa, M.Sc. Engenharia Florestal - Departamento de Ciências Florestais - Universidade Federal de Lavras/UFLA - Cx.P. 3037 - $37200-000$ Lavras, MG - idmfh@hotmail.com

'Engenheiro Florestal, Professor do Departamento de Ciências Florestais - Universidade Federal de Lavras/UFLA - Cx.P. 3037 - $37200-000$ - Lavras, MG - Doutorado; MS - j.aldo@ufla.br

${ }^{4}$ Engenheiro Agrônomo, Professor do Departamento de Ciência dos Solos - Universidade Federal de Lavras/UFLA - Cx.P. 3037 - $37200-000$ - Lavras, MG - PhD; MS - jmarques@ufla.br

${ }^{5}$ Engenheiro Florestal, Professor do Departamento de Ciências Florestais - Universidade Federal de Lavras/UFLA - Cx.P. 3037 - $37200-000$ - Lavras, $\mathrm{MG}$ - PhD; MS - passarinho@ufla.br
} 
associação regular e podem constituir unidades de mapeamento.

Em seus trabalhos, Cunha (2000) e Pocay (2000) mostraram a direta relação existente entre os diferentes tipos de erosão e a variabilidade das propriedades do solo, as quais, por sua vez, variam de acordo com a forma da paisagem (Silva et al., 1993). Desse modo, o entendimento dessas formas e da declividade pode auxiliar na identificação dos atributos dos solos dominantes em uma determinada área (Souza et al., 2003). Esses parâmetros são úteis para realizar a caracterização das associações de solos dominantes em uma área especifica.

Os sistemas de informações geográficas (SIGs) se constituem em um grupo de "ferramentas" específicas para coleta, tratamento, recuperação, visualização, armazenamento e análise de dados georreferenciados com vistas a obter informações nas mais diversas áreas do conhecimento científico (Castanho et al., 2005). A utilização dos SIGs é ideal para o acompanhamento da dinâmica da utilização das terras e para a análise espacial dos objetos ao longo do tempo, sendo considerada uma importante ferramenta para auxiliar na caracterização dos solos, pois possibilita a minimização do custo e do tempo da manipulação de mapas e da investigação de áreas, além de maximizar a qualidade e precisão dos resultados fornecidos (Silva et al., 2003).

Em virtude da atual escassez de dados, neste trabalho, objetivou-se realizar o levantamento de reconhecimento de média intensidade dos solos, com apoio digital, do Município de Nazareno-MG (escala 1:100.000), fornecendo subsídios para futuros mapeamentos mais detalhados dos solos desse município.

\section{Descrição da área}

O trabalho foi realizado no Município de NazarenoMG (21 $21^{\circ} \mathrm{S}$ e $\left.44^{\circ} 61^{\prime} \mathrm{W}\right)$ que possui altitude média de 935 m e área de $328 \mathrm{~km}^{2}$ e encontra-se inserido na superfície Cristalina do Alto Rio Grande, Bacia do Rio Grande (Marques et al., 2002).

Nazareno é caracterizado por um clima tropical de altitude com a ocorrência de verões quentes e úmidos e invernos frescos e secos. As chuvas ocorrem concentradas nos meses de novembro a fevereiro, com uma precipitação média anual de 1.200 a $1.500 \mathrm{~mm}$. Segundo a classificação de Köppen, o clima predominante é o Cwa com uma temperatura média anual de 18 a $19^{\circ} \mathrm{C}$ (Antunes, 1986).
A região corresponde a um mosaico vegetacional composto por um ecótono entre duas fisionomias vegetais distintas: floresta estacional semidecidual e cerrado tropical semidecidual (IBGE, 1992). Podem ser encontrados, ocasionalmente, campos hidrófilos de várzea nas baixadas (Giarola et al., 1997).

O relevo local possui em geral um padrão de dissecação homogêneo com drenagem de densidade média a grosseira. É caracterizado por colinas com topos convexos e tabulares e encostas convexas intercaladas por cristas alongadas e, geralmente, assimétricas, com declividades de 10 a $50 \%$ e planícies de inundação normalmente estreitas (Centro Tecnológico de Minas Gerais, 1983).

\section{Materiais Utilizados e Metodologia}

A base cartográfica utilizada foi as cartas planialtimétricas São João Del Rey, Folha SF-23-X-C-II-1; Nazareno, Folha SF-23-X-C-I-2; Madre de Deus de Minas, Folha SF 23-X-C-II-3 e Itutinga, Folha SF 23-X-C-I-4, em escala 1:50.000, editadas pelo IBGE em 1969.

Com base em curvas de nível eqüidistantes de 20 $\mathrm{m}$, digitalizadas das cartas planialtimétricas, foi gerado um modelo digital de elevação (MDE), derivado da triangulação dos valores dos dados hipsométricos. Obteve-se uma malha triangular irregular que, convertida para o formato raster, originou o MDE com resolução espacial de $30 \times 30 \mathrm{~m}$.

Por meio do cálculo da primeira derivada do MDE, gerou-se um mapa representativo da declividade do terreno. Os intervalos entre as classes de declividade foram definidos de acordo com Lemos \& Santos (1996) e correlacionados ao relevo. Em razão da ausência de fotos aéreas foi definida, com base no MDE, uma legenda preliminar dos pedoambientes ocorrentes em Nazareno.

Para a realização do levantamento dos solos do município, foram realizados trabalhos de campo que permitiram a conferência da legenda preliminar, por meio da observação da paisagem e dos solos do município, e a descrição três perfis representativos com coleta de sete amostras para a caracterização física e química por meio de análises laboratoriais. A análise granulométrica foi realizada após dispersão da amostra com $\mathrm{NaOH}$ mol L-1 e agitação rápida por 15 minutos, tendo a argila sido determinada pelo método do densímetro (Embrapa, 1997). Os componentes do complexo sortivo, $\mathrm{pH}$ em água e teor de C orgânico foram avaliados segundo Embrapa 
(1997), assim como os teores de $\mathrm{Zn}, \mathrm{Fe}, \mathrm{Mn}, \mathrm{Cu}$, B e S Os teores de $\mathrm{SiO}_{2}, \mathrm{Al}_{2} \mathrm{O}_{3}, \mathrm{Fe}_{2} \mathrm{O}_{3}, \mathrm{TiO}_{2}$ e $\mathrm{P}_{2} \mathrm{O}_{5}$ foram determinados por meio de ataque sulfúrico (Embrapa, 1997).

Três perfis foram descritos de acordo com Lemos \& Santos (1996) e classificados com base no Sistema Brasileiro de Classificação de Solos (Embrapa, 2006). Os resultados encontrados foram sobrepostos ao mapa de classes de declividade, o que resultou em um mapa de unidade de solos e suas fases de relevo.

A altitude no Município de Nazareno varia entre 839 e 1140 m. As áreas de menores elevações situam-se a oeste e se relacionam às áreas das várzeas do Rio Grande. As maiores elevações estão situadas a nordeste, na Serra Negra. A partir dos dados de declividade (Tabela 1), verificase que a maior parte do município possui relevo ondulado. Na sequência, tem-se os relevos suave-ondulado $(21,3 \%)$ e plano $(10,8 \%)$ e o forte ondulado $(1,9 \%)$. Em Nazareno, observou-se que não ocorrem relevos montanhosos e escarpados.

Assim como a altitude, a declividade também possui seus valores mais elevados, relevo forte-ondulado, a nordeste do município. As áreas planas encontram-se mais bem distribuídas no município, considerando que nelas inserem-se, além das áreas de várzea, os topos de morros.

Por sua vez, o mapa de solos do Município de Nazareno destacou cinco unidades de mapeamento as quais estão subdivididas em 15 unidades de acordo com as fases de relevo em que se inserem. Nessas, estão inseridas sete classes de solos (Figura 1, Tabelas 2 e 3 ).

Dentre as unidades de mapeamento definidas para Nazareno, houve predominância da denominada LVAd (58\%), formada por $50 \%$ de LVAd, $35 \%$ de CXbd e
$15 \%$ de LVd. Entre as quatro fases que compõem a unidade LVAd, a de maior área é a LVAd3 (41\%) que é caracterizada pela fase de relevo ondulado e é a maior unidade encontrada no levantamento. Sequencialmente, têm-se as unidades de mapeamento CXbd 4 a $6(16 \%)$ com $75 \%$ de CXbd e $25 \%$ de LVAd, a qual possui a terceira maior unidade encontrada, a CXbd5 (10\%); e CXbd 1 a 3 (15\%) com $80 \%$ de CXbd e $20 \%$ de RLd que conta com a unidade CXbd02 (8\%) que é a quarta mais abrangente. A unidade de mapeamento LVdf 1 a 4 (7\%) é formada por $50 \%$ de LVdf, $25 \%$ de CXbd e $25 \%$ de LVAd e ocorre na parte norte do município e a GXbd é a que ocupa a menor área em Nazareno (2\%), sendo formada por GXbd e RYbd indiscriminados (Tabela 4). O município possui $2 \%$ de lâmina d'água correspondendo ao reservatório da Usina Hidrelétrica de Camargos. Observa-se que à exceção da unidade GXbd, em todas as unidades de mapeamento as que se destacaram, com maior área, pertencem à fase de relevo ondulado.

Multiplicando-se a fração porcentual de cada classe encontrada nas referidas unidades, pela área total do município, tem-se como resultado a predominância dos CXbd (classe de solos dominante no Município de Nazareno-MG) sobre os LVAd, observando-se que, ainda assim, a unidade de mapeamento que abrange a maior área no município é a LVAd1 a 4 (Tabelas 2 e 4).

As áreas dominadas pela unidade GXbd são as que possuem os menores valores de altitude e declividade. Isso é compreendido sabendo-se que os solos da referida unidade ocorrem, especificamente, nas áreas de várzeas do município concordando com Resende et al. (2002) que afirmam que tais classes apresentam, geralmente, topografia plana e são comuns em terrenos baixos ou em terços inferiores de encostas pouco declivosas.

Tabela 1 - Classes de declividade com o tipo do relevo e a área correspondente ocupada no Município de Nazareno para cada classe.

\begin{tabular}{cccc}
\hline Classes de declividade $(\%)$ & Relevo & Área $\left(\mathrm{km}^{2}\right)$ & Área $(\%)$ \\
\hline $0-3$ & Plano & 35,6 & 10,8 \\
$3-8$ & Suave Ondulado & 69,8 & 21,3 \\
$8-20$ & Ondulado & 209,7 & 63,9 \\
$20-45$ & Forte ondulado & 6,13 & 1,9 \\
\hline
\end{tabular}




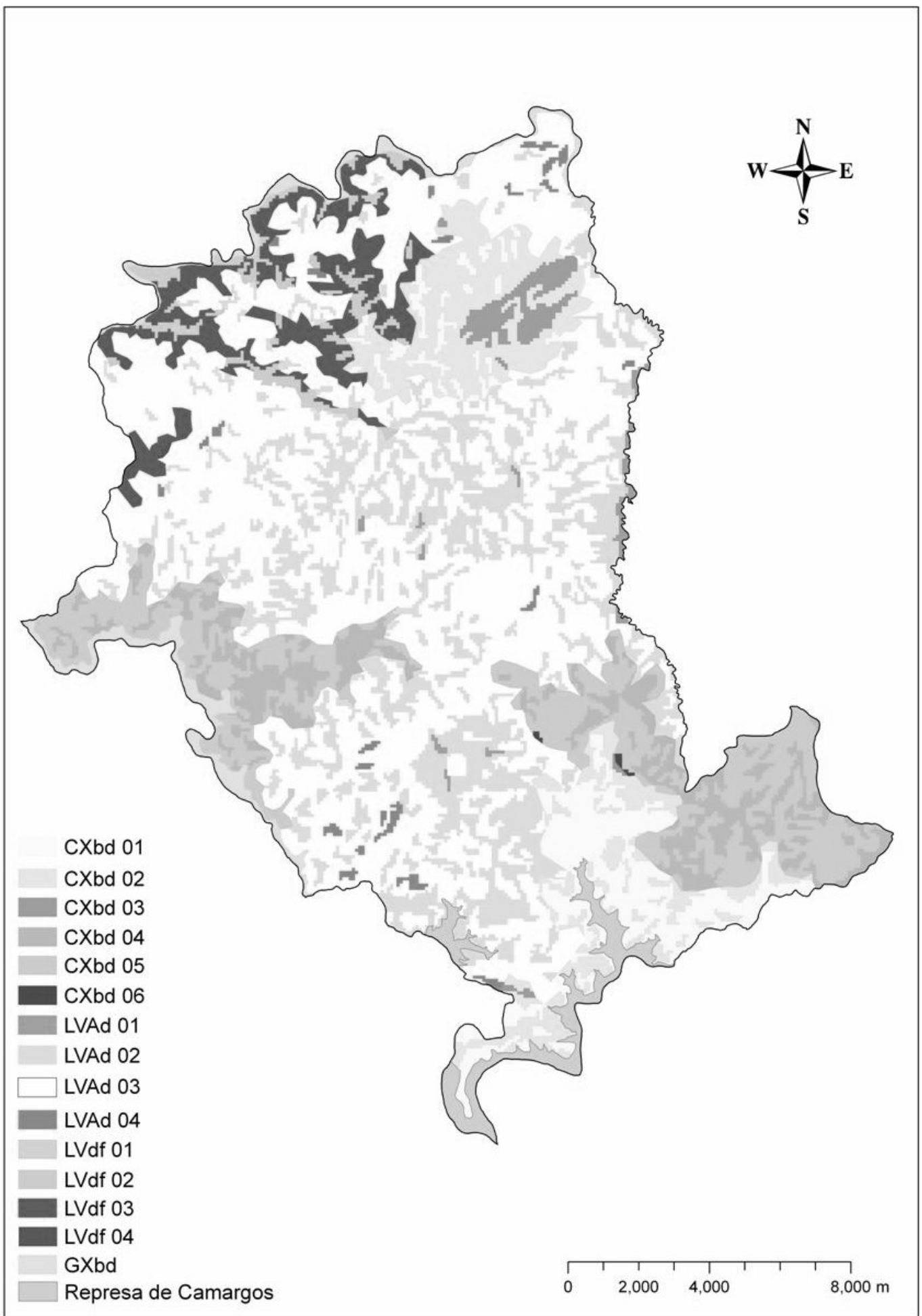

Figura 1 - Mapa de unidades de solos do Município de Nazareno-MG. 
HORTA, I. de M. F. et al.

Tabela 2 - Classes e porcentuais das unidades de mapeamento de solos encontradas no Município de Nazareno-MG.

\begin{tabular}{cl}
\hline Unidades & \multicolumn{1}{c}{ Classes e porcentuais que as compõem } \\
\hline CXbd 1 a 3 & $80 \%$ CXbd $+20 \%$ RLd \\
CXbd 4 a 6 & $75 \%$ CXbd $+25 \%$ LVAd \\
GXbd & GXbd e RYbd indiscriminados \\
LVAd 1 a 4 & $50 \%$ LVAd $+25 \%$ CXbd $+25 \%$ LVd \\
LVdf 1 a 4 & $50 \%$ LVdf $+25 \%$ CXbd $+25 \%$ LVAd \\
\hline
\end{tabular}

Tabela 3 - Classes de solo encontradas no Município de Nazareno-MG.

\begin{tabular}{cl}
\hline Classe & \multicolumn{1}{c}{ Descrição } \\
\hline LVAd & $\begin{array}{l}\text { Latossolo Vermelho-Amarelo distrófico típico argiloso a muito argiloso A moderado } \\
\text { Latossolo Vermelho distroférrico húmico e típico muito argiloso A moderado e A húmico } \\
\text { alumínico }\end{array}$ \\
LVd & Latossolo Vermelho distrófico típico argiloso a muito argiloso A moderado \\
CXbd & Cambissolo Háplico Tb distrófico típico argiloso A moderado alumínico \\
GXbd & Gleissolo Háplico Tb distrófico típico \\
RYbd & Neossolo Flúvico Tb distrófico típico \\
RLd & Neossolo Litólico distrófico típico
\end{tabular}

Tabela 4 - Área ocupada pelas unidades de solos com suas respectivas fases de relevo, mapeadas no Município de Nazareno-MG.

\begin{tabular}{|c|c|c|c|c|c|c|}
\hline $\begin{array}{l}\text { Unidades de } \\
\text { Mapeamento }\end{array}$ & $\mathrm{km}^{2}$ & $\%$ & unidades & Fases do Relevo & $\mathrm{km}^{2}$ & $\%$ \\
\hline \multirow{4}{*}{ LVAd 1 a 4} & \multirow{4}{*}{192,3} & \multirow{4}{*}{58} & LVAd1 & Plano & 1,2 & 0,4 \\
\hline & & & LVAd2 & Suave-ondulado & 54,7 & 16,7 \\
\hline & & & LVAd3 & Ondulado & 133,8 & 41 \\
\hline & & & LVAd4 & Forte-ondulado & 2,1 & 0,6 \\
\hline \multirow{4}{*}{ LVdf 1 a 4} & \multirow{4}{*}{21,6} & \multirow{4}{*}{7} & LVdf1 & Plano & 0,24 & 0,1 \\
\hline & & & LVdf2 & Suave-ondulado & 5,2 & 1,6 \\
\hline & & & LVdf3 & Ondulado & 15,8 & 4,8 \\
\hline & & & LVdf4 & Forte-ondulado & 0,08 & 0,02 \\
\hline \multirow{3}{*}{ CXbd 1 a 3} & \multirow{3}{*}{48,9} & \multirow{3}{*}{15} & CXbd1 & Plano e suave-ondulado & 18,3 & 5,6 \\
\hline & & & $\mathrm{CXbd} 2$ & Ondulado & 26,8 & 8,2 \\
\hline & & & $\mathrm{CXbd} 3$ & Forte-ondulado & 3,8 & 1,2 \\
\hline \multirow{3}{*}{ CXbd 4 a 6} & \multirow{3}{*}{52,6} & \multirow{3}{*}{16} & CXbd4 & Plano e suave-ondulado & 19,1 & 5,8 \\
\hline & & & CXbd5 & Ondulado & 33,3 & 10 \\
\hline & & & CXbd6 & Forte-ondulado & 0,15 & 0,05 \\
\hline GXbd & 6,7 & 2 & GXbd & Plano e suave-ondulado & 6,7 & 2,0 \\
\hline \multicolumn{3}{|c|}{ Represa de Camargos (água) } & & & 6,7 & 2,0 \\
\hline Total & 328 & 100 & & & 328 & 100 \\
\hline
\end{tabular}


Em razão da sua relevância para o Município, serão descritas e analisadas a seguir as classes de solos de maior dominância em Nazareno-MG:

CXbd (Cambissolo): Os Cambissolos em Nazareno possuem argila de baixa atividade ( $\mathrm{Tb}$ ) e o valor $\mathrm{V}$ abaixo de $50 \%$. O resultado das análises granulométricas realizadas para este solo o classifica da seguinte forma: horizonte $\mathrm{A}$, textura média e os horizontes $\mathrm{Bi}$ e $\mathrm{C}$, textura argilosa (370 $\mathrm{g} \mathrm{kg}^{-1}$ e $390 \mathrm{~g} \mathrm{~kg}^{-1}$ de argila, respectivamente), corroborando com os valores texturais encontrados por Ferreira (2005), cujos resultados são coincidentes. Os valores de $\mathrm{Kr}$ encontrados $(\mathrm{A}=1,19 ; \mathrm{Bi}=1,07$ e $\mathrm{C}=1,18)$, superiores a 0,75 , e de $\mathrm{Ki}(\mathrm{A}=1,29 ; \mathrm{Bi}=1,15$ e $\mathrm{C}=1,26)$, mostram a intensa remoção de sílica do perfil concomitante à acumulação residual de sesquióxidos, particularmente, de alumínio. O horizonte A é do tipo moderado e é alumínico, com baixo índice de saturação por bases (19\%), elevado índice de saturação por $\mathrm{Al}(69 \%)$ e pequena espessura (20 cm) (Tabela 5). Esses são Cambissolos característicos das encostas declivosas do chamado "mar-de-morros" (Resende et al., 2002). Esses Cambissolos são formados pelo estreitamento progressivo do horizonte B latossólico, situado no topo dos morros florestados, à medida que se caminha em direção ao terço médio das encostas. Dessa forma, o horizonte B incipiente desses Cambissolos é muito semelhante a um horizonte B latossólico, diferindo deste basicamente pela espessura inferior a $50 \mathrm{~cm}$.

Os Cambissolos predominam principalmente ao sul do município, em relevo mais movimentado, ondulado e forte-ondulado. São mais rasos quando comparados aos
Latossolos e muito erodidos (Carvalho et al., 1994). À medida que se aproxima da Represa de Itutinga/Camargos, observa-se um aumento da contribuição de rochas pelíticas e de quartzito sobre o granito-gnaisse, fator que colabora, geralmente, para a presença de solos mais pobres, rasos e de maior potencial erosivo. Associada a essas áreas, observa-se a presença de vegetação graminóide e campestre.

Uma prática comum utilizada na região é a queima das pastagens nativas, o que expõe ainda mais esses solos no início das chuvas ao impacto direto das gotas de chuva, fazendo com que eles tenham sérios problemas de erosão, corroborando com os estudos de Carvalho et al. (1994). Segundo esses estudos, neste tipo de paisagem o número de voçorocas é elevado. Os principais fatores limitantes à produção agrícola referem-se à extrema pobreza química e à elevada susceptibilidade à erosão dos Cambissolos (Curi, 1991; Ferreira, 2005).

LVAd (Latossolo Vermelho-Amarelo): Os valores encontrados nas análises químicas, no horizonte A ( $\mathrm{V}=$ $18 \%$ ) e no Bw ( $\mathrm{V}=28 \%$ ), determinam solos distróficos, concordando com a classificação encontrada por Ferreira (2005) para o município. O resultado da análise granulométrica denota solos argilosos $\left(430 \mathrm{~g} \mathrm{~kg}^{-1}\right.$ de argila no horizonte A e $470 \mathrm{~g} \mathrm{~kg}^{-1}$ no horizonte $\mathrm{Bw}$ ). Os valores encontrados por Ferreira (2005) demonstram a presença de LVAs também com textura muito argilosa. Os valores do $\mathrm{Kr}$ para os dois horizontes são superiores a $0,75(\mathrm{~A}=1,03$ e $\mathrm{Bw}=1,06)$ e de $\mathrm{Ki}$ inferiores a 2,2 $(\mathrm{A}=1,40$ e $\mathrm{Bw}=1,42)$, assim, esse solo é considerado enriquecido residualmente

Tabela 5 - Atributos granulométricos e químicos dos solos do Município de Nazareno-MG.

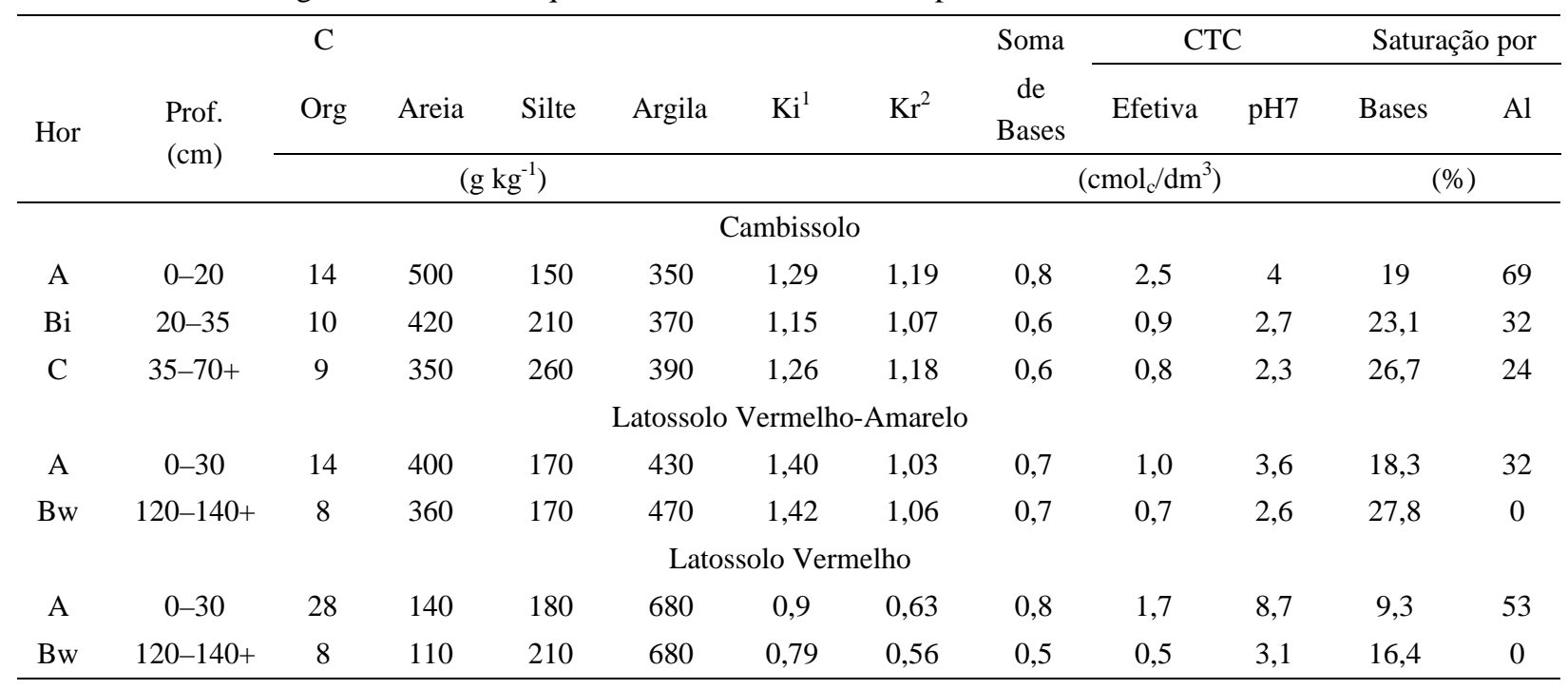


em sesquióxidos, com baixos teores de $\mathrm{SiO}_{2}$ e teores mais elevados de $\mathrm{Al}_{2} \mathrm{O}_{3}$ (Tabela 5).

LVd (Latossolo Vermelho): Essa classe de LV foi encontrada por Ferreira (2005) na unidade aqui mapeada e denominada de LVAd 01 a 04. É distrófico e possui em todas as amostras coletadas valores de $\mathrm{V}$ abaixo de 50\%. Apresenta textura argilosa e muito argilosa com os teores de argila, variando entre 550 e $730 \mathrm{~g} \mathrm{~kg}^{-1}$ (Tabela 6).

Tabela 6 - Resultados de análises realizadas por Ferreira (2005), dados de V e argila de um Latossolo Vermelho distrófico.

\begin{tabular}{ccccc}
\hline \multirow{2}{*}{ Perfil } & \multirow{2}{*}{ Horizonte } & Prof. $(\mathrm{m})$ & $\mathrm{V}$ & Argila \\
\cline { 4 - 5 } & & & $\%$ & $\mathrm{~g} \mathrm{~kg}^{-1}$ \\
\hline \multirow{2}{*}{2} & A & $0-0,2$ & 26,7 & 550 \\
& Bw & $1,2-1,6$ & 45,3 & 650 \\
& A & $0-0,2$ & 20,3 & 570 \\
3 & Bw & $0,9-1,2$ & 37,8 & 610 \\
& A & $0-0,2$ & 35 & 680 \\
& Bw & $60-90$ & 18,6 & 730 \\
\hline
\end{tabular}

LVdf (Latossolo Vermelho): Este é um LV que, em razão do elevado teor de $\mathrm{Fe}_{2} \mathrm{O}_{3}$ somado ao baixo valor $\mathrm{V}$ em ambos os horizontes, possui características distroférricas. É um solo muito argiloso e homogêneo com teores de argila iguais a $680 \mathrm{gkg}^{-1} \mathrm{em}$ ambos os horizontes. Possui baixos valores de $\mathrm{Ki}$ e $\mathrm{Kr}$, os quais denotam um solo ferralítico, ou seja, com pouca presença de $\mathrm{SiO}_{2}$ e teores elevados de $\mathrm{Al}_{2} \mathrm{O}_{3}$ e $\mathrm{Fe}_{2} \mathrm{O}_{3}$, muito intemperizado. Esses índices estão em concordância com a característica distroférrica do referido solo e álica do horizonte A do mesmo (Tabela 5).

Os Latossolos Vermelho-Amarelos estão distribuídos mais uniformemente e os Latossolos Vermelhos ocorrem em relevo dominantemente suaveondulado e ondulado, com pendentes mais longas, sendo mais profundos que os vermelho-amarelos (Carvalho et al., 1994). Proporcionalmente, observa-se maior presença de pastagens nos Latossolos Vermelho-Amarelos e de culturas nos Latossolos Vermelhos. Os Latossolos Vermelhos distroférricos predominam na parte norte do município onde as formações florestais são mais frequentes.

As classes de solo mais comuns são os Latossolos Vermelho-Amarelos distróficos típicos argilosos a muito argilosos A moderado e os Cambissolos Háplicos Tb distróficos típicos argilosos A moderado alumínicos. Existe uma alternância na dominância dessas classes em todo o ambiente.

Os resultados encontrados fornecem subsídios para futuros mapeamentos da área e para possíveis ações que minimizem os processos erosivos ocorrentes na mesma.

\section{REFERÊNCIAS BIBLIOGRÁFICAS}

ANTUNES, F.Z. Caracterização climática do Estado de Minas Gerais. Informe Agropecuário, Belo Horizonte, v.12. n.138, p.9-13, 1986.

\section{BERTONI, J.; LOMBARDI NETO, F. Conservação do} solo. São Paulo: Ícone, 1990. 355p.

CARVALHO, M.M.; EVANGELISTA, A.R.; CURI, N. Desenvolvimento de pastagens na zona fisiográfica Campo das Vertentes, MG. Lavras: ESAL; Coronel Pacheco: Embrapa.-CNPGL, 1994. 127p.

CASTANHO, R.B.; BEZZI, M.L.; CASSOL, R.

Geoprocessamento x planejamento físico territorial: o caso do distrito de São Bento (Palmeiras das Missões/ RS). In: SIMPÓSIO BRASILEIRO DE

SENSORIAMENTO REMOTO, 12., 2005, Goiânia, GO. Anais... Goiânia: INPE, 2005. p.21943-1950.

\section{CENTRO TECNOLÓGICO DE MINAS GERAIS.}

Diagnóstico ambiental do Estado de Minas Gerais. Belo Horizonte, 1983. 158p.

CUNHA, P. Superfície geomórfica e variabilidade de Latossolos em uma vertente sobre arenito-basalto em Jaboticabal, SP. 2000. 149p. Tese (Doutorado em Agronomia)-Universidade Estadual Paulista, Jaboticabal, 2000.

CURI, N. Relações solo-pastagens na região dos Campos das Vertentes (MG). Lavras: Embrapa/CNPGL, 1991. 24p. Relatório.

CURI, N.; FRANZMEIER, D.P. Toposequence of oxisols from the central plateau of Brazil. Soil Science Society American Journal, Madison, v.48, p.341-346, 1984.

\section{EMPRESA BRASILEIRA DE PESQUISA}

AGROPECUÁRIA. Centro Nacional de Pesquisa de Solos. Manual de métodos de análise de solo. 2.ed. rev. Rio de Janeiro, 1997. 212p. 
EMPRESA BRASILEIRA DE PESQUISA AGROPECUÁRIA. Sistema brasileiro de classificação de solos. 2.ed. Brasília, DF: Embrapa, 2006. 306p.

FANNING, D.S.; FANNING, M.C.B. Soil: morphology, genesis and classification. New York: J.Wiley, 1989. 395p.

FERREIRA, V.M. Voçorocas no município de Nazareno, MG: origem, uso da terra e atributos do solo. 2005. 84p. Dissertação (Mestrado em Agronomia)-Universidade Federal de Lavras, Lavras, 2005.

GALETI, P.A. Conservação do solo-reflorestamentoclima. Campinas: Instituto Campineiro de Ensino Agrícola, 1989. 286p.

GIAROLA, N.F.B. et al. Solos da região sob influência do reservatório da hidrelétrica de Itutinga/Camargos (MG): perspectiva ambiental. Lavras: CEMIG, 1997. 101p.

\section{INSTITUTO BRASILEIRO DE GEOGRAFIA E}

ESTATÍSTICA. Manual técnico da vegetação brasileira. Rio de Janeiro, 1992. 92p. (Manuais técnicos em geociências).

LEMOS, R.C.; SANTOS, R.D. Manual de descrição e coleta de solo no campo. 3.ed. Campinas: Sociedade Brasileira de Ciência do Solo, 1996. 84p.
MARQUES, J.J.G.S.M.; CURI, N.; LIMA, J.M. Recursos ambientais da Bacia do Alto Rio Grande, Minas Gerais. Lavras: UFLA/FAEPE, 2002. 33p.

POCAY, V.G. Relações entre pedoformas e variabilidade espacial de atributos de Latossoslos sob cultivo de cana-deaçúcar. 2000. 177p. Dissertação (Mestrado em Agronomia)Universidade Estadual Paulista, Jaboticabal, 2000.

RESENDE, M. et al. Pedologia: base para a distinção de ambientes. 4.ed. Viçosa, MG: NEPUT, 2002. 338p.

SANTOS, R.F. Planejamento ambiental: teoria e prática. São Paulo: Oficina de Textos, 2004. 184p.

SILVA, A.C.; LIMA, J.M.; CURI, N. Relação entre voçorocas, usos da terra, solos e materiais de origem na região de Lavras (MG). Revista Brasileira de Ciência do Solo, Campinas, v.17, p.459-464, 1993.

SILVA, A.M.; SCHULZ, H.E.; CAMARGO, P.B. Erosão e hidrossedimentologia em bacias hidrográficas. São Carlos: RIMa, 2003. 140p.

SOUZA, C.K. et al. Influência do relevo e erosão na variabilidade espacial de um Latossolo em Jaboticabal (SP). Revista Brasileira de Ciência do Solo, Campinas, v.27, n.6, p.1067-1074, nov./dez. 2003. 